\title{
Marketplace Analysis of Conjugated Estrogens: Determining the Consistently Present Steroidal Content with LC-MS
}

\author{
Michaella J. Levy, ${ }^{1}$ Michael T. BoyneII, ${ }^{1,4}$ Sarah Rogstad, ${ }^{1}$ David J. Skanchy, ${ }^{2}$ \\ Xiaohui Jiang, ${ }^{3}$ and Ilan Geerlof-Vidavsky ${ }^{1,5}$
}

Received 2 April 2015; accepted 14 July 2015; published online 5 August 2015

\begin{abstract}
Conjugated estrogens purified from pregnant mares urine has been used as estrogen hormone replacement therapy since 1942. Previously, methods were proposed to identify and quantify the components of this complex mixture but ultimately were withdrawn due to incomplete characterization of the product and difficulties in transferring the method between laboratories. The aim of the current study is to develop a LC method that can reliably detect multiple steroidal components in conjugated estrogen tablets and measure their relative amount. The method developed was optimized for UHPLC columns, and the elution profile was analyzed using high-resolution mass spectrometry. A total of 60 steroidal components were identified using their exact $\mathrm{m} / \mathrm{z}$, product ion spectra of known, and predicted conjugated estrogen structures. These components were consistently present in 23 lots of Premarin tablets spanning two production years. The ten conjugated estrogens identified in the USP monograph and other additional estrogens reported elsewhere are among the 60 steroidal components reported here. The LC-MS method was tested in different laboratories using multiple samples, and the obtained results were reproducible among laboratories.
\end{abstract}

KEY WORDS: conjugated estrogens; mass spectrometry; steroidal content.

\section{INTRODUCTION}

Conjugated estrogens, US Pharmacopeia (USP), is a mixture of a substantial number of mostly sulfated estrogens and other steroids with pharmacological activity. The sulfated steroids do not have pharmacological activity but are slowly converted to free steroids and some steroids are converted to other ones, e.g., estrone to estradiol. The steroidal mixture

Michaella J. Levy and Michael T. Boyne II contributed equally to this work.

Electronic supplementary material The online version of this article (doi:10.1208/s12248-015-9805-x) contains supplementary material, which is available to authorized users.

\footnotetext{
${ }^{1}$ Division of Pharmaceutical Analysis, Office of Testing and Research, Center for Drug Evaluation and Research, U.S. Food and Drug Administration, 645 S. Newstead Avenue, St. Louis, Missouri 63110, USA.

${ }^{2}$ Office of New Drug Products, Office of Pharmaceutical Quality, Center for Drug Evaluation and Research, U.S. Food and Drug Administration, 10903 New Hampshire Ave, Silver Spring, Maryland 20993, USA.

${ }^{3}$ Office of Research and Standards, Office of Generic Drugs, Center for Drug Evaluation and Research, U.S. Food and Drug Administration, 10903 New Hampshire Ave, Silver Spring, Maryland 20993, USA.

${ }^{4}$ Present Address: Biotechlogic, Inc., Glenview, Illinois, USA.

${ }^{5}$ To whom correspondence should be addressed. (e-mail: ilan.geerlofvidavsky@fda.hhs.gov)
}

binds estrogen receptors (ER- $\alpha$ and ER- $\beta$ ) expressed on the surface of a number of cell types, which, upon conformational change, can affect post translation modifications (i.e. phosphorylation), cell signaling, transcriptional activity, and receptor stability $(1,2)$. The binding affinities of the steroids in the mixture vary based on stereotype and receptor $(2,3)$. Conjugated estrogens are prescribed for estrogen replacement therapy (2) to treat menopausal symptoms (4) and to prevent post-menopausal osteoporosis $(5,6)$. Additional uses in both men and women indicate conjugated estrogens slow the progression of breast and prostate metastasized cancer (7).

The high complexity of the chemical composition and lack of consistent identification of the components of conjugated estrogens have been a barrier for defining active components of the active pharmaceutical ingredient (API) and prevented the approval of generics. The current USP monograph for conjugated estrogens requires the quantification of only a small subset of ten components, sodium estrone sulfate, sodium equilin sulfate, sodium $\Delta^{8,9}$-dehydroestrone sulfate, sodium equilenin sulfate, sodium $17 \alpha$-estradiol sulfate, sodium $17 \beta$-estradiol sulfate, sodium $17 \alpha$-dihydroequilin sulfate, sodium $17 \beta$-dihydroequilin sulfate, sodium $17 \alpha$ dihydroequilenin sulfate, and sodium $17 \beta$-dihydroequilenin sulfate, and therefore does not include many of the additional possible active components (8). For example, an additional 7 estrogenic, 7 pregnane metabolites, and 4 androgen metabolites have been identified previously (9). A path toward the approval of generic conjugated estrogen products was 
outlined in a 1997 memo by Dr. Janet Woodcock of the FDA in which the importance of providing a detailed chemical composition of the drug product was highlighted (10).

Separation and identification of Premarin components by LC-MS were shown previously to resolve isomers in conjugated estrogens, namely equilin sulfate and $\Delta^{8,9}$ dehydroestrone sulfate (11). A draft guidance for industry, based on this method, was published by the FDA in 2000 for qualitative chemical characterization of conjugated estrogens and demonstration of pharmaceutical equivalence. However, the method was not robust and was withdrawn at a later time (11). Additional analyses by gas chromatography mass spectrometry (GC-MS) are sensitive to identify certain steroidal components, but the sample preparation requires derivatization prior to analysis, which may combine different conjugated forms into a single peak only representing the core steroidal structure $(12,13)$.

In recent years, analytical separation techniques and mass spectrometer performance have improved to the point that the LC-MS approach was re-examined with state-of-theart instrumentation available within FDA laboratories. With the introduction of UHPLC systems and faster, more sensitive, and higher resolution mass spectrometers, we expected to improve upon past quantitative and qualitative assessments of conjugated estrogens. The goal of this work was to establish a LC-MS method suitable to identify the steroidal components in conjugated estrogen tablets that were consistently present in multiple lots of conjugated estrogens in an effort to develop a robust set of assays that may be disseminated to the public and facilitate the development of generic conjugated estrogens products. The 23 lots of samples analyzed span 2 years of production and are expected to encompass the current biological variability associated with the production process. The large number of steroidal components defined in this work and the measurements of their relative contents may provide a scientific method to assess the sameness of active ingredients for conjugated estrogens products.

\section{MATERIALS}

Twenty-three lots of Premarin tablets (conjugated estrogens tablets, USP) were purchased from pharmacies in the USA. These lots were manufactured over a 2 -year period in different strengths (0.3 to $1.25 \mathrm{mg})$. The lots tested are summarized in Supplemental Table 1. Synthetic standards of estrone-3-sulfate sodium salt (E1-S), equilin-3-sulfate sodium salt $(\mathrm{EqS}), \Delta^{8,9}$-dehydroestrone-3-sulfate sodium salt (DHES), equilenin-3-sulfate sodium salt (EqnS), dihydroestrone-17 $\alpha$-3-sulfate sodium salt (E2-3S-17a), dihydroestrone-17 $\beta-3$-sulfate sodium salt (E2-3S-17b), dihydroequilin-17 $\alpha$-3-sulfate sodium salt (DEq3S17a), dihydroequilin-17 $\beta$-3-sulfate sodium salt (DEq3S17b), dihydroequilenin-17 $\alpha$-3-sulfate sodium salt (DEqn3S17a), and dihydroequilenin-17 $\beta-3$-sulfate sodium salt (DEqn3S17b) from Steraloids (Newport, RI) were used to optimize chromatography and for identifying of compounds using product ion spectra. All solvents and DI water were purchased from Fisher Scientific (Pittsburg, PA) and were LC-MS Optima grade unless otherwise noted.

\section{METHODS}

\section{Sample Preparation}

Multiple tablets were processed to obtain at least $3.6 \mathrm{mg}$ of conjugated estrogens based on label claim amounts. For example, six tablets were processed for the $0.625-\mathrm{mg}$ strength tablet. Tablets were weighed to determine an average weight per tablet. The tablets were placed in a 50-mL Erlenmeyer flask, and $15 \mathrm{~mL} 18 \mathrm{M} \Omega$ deionized (DI) water was added. The vessel was shaken on an orbital shaker at room temperature until the outer coating was dissolved. The water was decanted, and another $15 \mathrm{~mL}$ of water was added to rinse. The rinse was discarded, and the tablets were transferred to a pre-weighted weigh boat. The tablets were dried in a vacuum oven for $45 \mathrm{~min}$ at room temperature. The tablets were weighed, and the process was repeated every 30 min until they reached a constant weight. The average weight of the washed tablets was determined, and then the tablets were ground or pulverized to a uniform powder. The equivalent of $0.6 \mathrm{mg}$ conjugated estrogens was transferred into a $125-\mathrm{mL}$ Erlenmeyer flask. Fifty milliliters of DI water was added, stoppered, and shaken at room temperature for $2 \mathrm{~h}$ until total dissolution. The solution was centrifuged at $3000 \times g$ for $15 \mathrm{~min}$ to remove any remaining solid particulates.

\section{Solid Phase Extraction}

Solid phase extraction (SPE) was performed with SepPak C18 cartridges, $500 \mathrm{mg}$ (Waters, Milford, MA). Each cartridge was conditioned with $3 \mathrm{~mL}$ methanol followed by $3 \mathrm{~mL} \mathrm{5 \%} \mathrm{methanol} \mathrm{solution} \mathrm{in} \mathrm{water.} \mathrm{The} \mathrm{sample} \mathrm{solution}$ was passed through the cartridge and then washed with additional $3 \mathrm{~mL}$ of $5 \%$ methanol solution in water. The bound sample was eluted with $3 \mathrm{~mL}$ of methanol and dried under nitrogen to an approximate final volume of $1 \mathrm{~mL}$. The resulting conjugated estrogen solution was syringe filtered through a $0.45-\mu \mathrm{m}$ nylon filter. For analysis, the sample was diluted $1: 5$ with $0.1 \%$ formic acid in water prior to injection.

\section{LC Method Optimization}

Four UHPLC column stationary phases (Acquity BEH C18, Acquity BEH Shield C18, Acquity BEH phenyl, and Acquity CSH Fluorophenyl) in the same column dimensions $(1.7 \mu \mathrm{m}, 2.1 \times 150 \mathrm{~mm})$ were assessed for their ability to resolve Equilin-3-sulfate sodium salt $(\mathrm{EqS})$ from $\Delta^{8,9}$ dehydroestrone-3-sulfate sodium salt (DHES), retention time reproducibility, and peak area reproducibility (Supplemental Figure 1, Supplemental Table 2).

\section{LC-MS}

Initially, the chromatography and mass spectrometry (MS) method was developed on an Agilent 6420 Triple Quad equipped with a 1290 UHPLC system in negative ion mode, gas temperature $300^{\circ} \mathrm{C}$, gas flow $6 \mathrm{~L} / \mathrm{min}$, spray voltage $-3.8 \mathrm{kV}$. To increase sensitivity and mass resolving power, the method was transferred to a Thermo Fisher Q-Exactive mass spectrometer equipped with Accella UHPLC system and HTC-PAL autosampler. One microliter was injected on 
the column, and the optimized gradient separation was performed with a Waters Acquity UPLC BEH C18 $(1.7 \mu \mathrm{m}$, $130 \AA, 2.1 \times 150 \mathrm{~mm}$ ) column heated to $40^{\circ} \mathrm{C}$ at a $0.35 \mathrm{~mL} / \mathrm{min}$ flow rate. Mobile phase A consisted of water with $0.1 \%$ formic acid. Mobile phase B consisted of methanol with $0.1 \%$ formic acid. The gradient began at $21 \% \mathrm{~B}$ and was raised to $33 \% \mathrm{~B}$ in $5 \mathrm{~min}, 53 \% \mathrm{~B}$ in $45 \mathrm{~min}$, and $98 \% \mathrm{~B}$ in $60 \mathrm{~min}$ where it was held for $5 \mathrm{~min}$ before re-equilibrating at $21 \% \mathrm{~B}$ for $5 \mathrm{~min}$. Column eluent was sprayed using a Thermo HESI II source operating at $300^{\circ} \mathrm{C}$ in negative ion mode. Source conditions were: sheath gas 50 (arb. units), auxiliary gas 10 (arb. units), spray voltage $-2.6 \mathrm{kV}$, capillary temperature $360^{\circ} \mathrm{C}$. The mass spectrometer was operated at a resolving power of 140,000 at $200 \mathrm{~m} / \mathrm{z}$ with a scan range from $250-700 \mathrm{~m} / \mathrm{z}$.

\section{LC-MS Data Analysis}

Using accurate mass and mass defects, the top 250 putative steroidal conjugates (sulfates and glucuronides) were identified. This list was generated for all 23 lots, and the top 60 consistently present peaks $>0.1 \%$ of the total peak area were identified. The masses for the extracted ion chromatograms were then determined from the known conjugated estrogens structures, the calculated $\mathrm{m} / \mathrm{z}$ of the predicted metabolites, and molecular composition determined by exact mass measurements leading to a list of $22 \mathrm{~m} / \mathrm{z}$ to monitor. These masses are listed in Table I. For each LC-MS run, a total of 60 distinct species were monitored using the 22 accurate $( \pm 5 \mathrm{ppm})$ extracted ion mass chromatograms. These were generated in Xcalibur and exported to Excel (retention time, $m / z$, and intensity) to evaluate lot-to-lot variability. Each sample was run in triplicate. The relative peak areas were normalized, and the retention times were averaged for the top 60 components observed in each chromatogram, which are listed in Table II.

\section{Statistical Analysis}

Box plots of the top 60 components were generated using SigmaPlot 12.3. The median is displayed as the black line within the box along with the 25 th and 75 th percentiles as the boundaries of the box and the 10th and 90th percentiles as the error bars.

Table I. List of Masses $(\mathrm{m} / \mathrm{z})$ to Generate Extracted Ion Mass Chromatograms (EIC)

\begin{tabular}{ll}
\hline$m / z$ Masses for EIC & \\
\hline 345.0802 & 379.1221 \\
347.0959 & 381.1377 \\
349.1115 & 385.1690 \\
351.1272 & 387.1847 \\
353.1428 & 395.1905 \\
355.1585 & 397.2060 \\
365.1064 & 399.2211 \\
367.1585 & 413.2005 \\
369.1741 & 415.2162 \\
371.1898 & 465.2501 \\
377.1064 & 511.2921 \\
\hline
\end{tabular}

Table II. Sixty Compounds Identified That Were Consistently Present in 23 Lots of Premarin

\begin{tabular}{|c|c|c|c|c|}
\hline Number & Name & Mass $m / z$ & Putative composition & RRt \\
\hline $1 \mathrm{a}$ & E1-S ${ }^{a}$ & 349.1115 & $\mathrm{C}_{18} \mathrm{H}_{22} \mathrm{O}_{5} \mathrm{~S}$ & 1.000 \\
\hline $1 b$ & $\mathrm{DEq} 3 \mathrm{~S} 17 \mathrm{a}^{\mathrm{a}}$ & & & \\
\hline 2 & $\mathrm{EqS}^{\mathrm{a}}$ & 347.0959 & $\mathrm{C}_{18} \mathrm{H}_{20} \mathrm{O}_{5} \mathrm{~S}$ & 0.937 \\
\hline 3 & 413@1.28 & 413.2003 & $\mathrm{C}_{21} \mathrm{H}_{34} \mathrm{O}_{6} \mathrm{~S}$ & 1.280 \\
\hline 4 & 399@2.25 & 399.2211 & $\mathrm{C}_{21} \mathrm{H}_{36} \mathrm{O}_{5} \mathrm{~S}$ & 2.250 \\
\hline 5 & 351@1.17 & 351.1272 & $\mathrm{C}_{18} \mathrm{H}_{24} \mathrm{O}_{5} \mathrm{~S}$ & 1.172 \\
\hline 6 & $\mathrm{E} 2-3 \mathrm{~S} 17 \mathrm{a}^{\mathrm{a}}$ & 351.1272 & $\mathrm{C}_{18} \mathrm{H}_{24} \mathrm{O}_{5} \mathrm{~S}$ & 1.184 \\
\hline 7 & 415@1.22 & 415.2162 & $\mathrm{C}_{21} \mathrm{H}_{36} \mathrm{O}_{6} \mathrm{~S}$ & 1.218 \\
\hline 8 & 353@1.34 & 353.1428 & $\mathrm{C}_{18} \mathrm{H}_{26} \mathrm{O}_{5} \mathrm{~S}$ & 1.341 \\
\hline 9 & 397@2.21 & 397.2054 & $\mathrm{C}_{21} \mathrm{H}_{34} \mathrm{O}_{5} \mathrm{~S}$ & 2.212 \\
\hline 10 & 415@0.63 & 415.2162 & $\mathrm{C}_{21} \mathrm{H}_{36} \mathrm{O}_{6} \mathrm{~S}$ & 0.629 \\
\hline 11 & $\mathrm{EqnS}^{\mathrm{a}}$ & 345.0802 & $\mathrm{C}_{18} \mathrm{H}_{18} \mathrm{O}_{5} \mathrm{~S}$ & 0.859 \\
\hline 12 & $\mathrm{DEHS}^{\mathrm{a}}$ & 347.0959 & $\mathrm{C}_{18} \mathrm{H}_{20} \mathrm{O}_{5} \mathrm{~S}$ & 0.921 \\
\hline 13 & 369@1.73 & 369.1741 & $\mathrm{C}_{19} \mathrm{H}_{30} \mathrm{O}_{5} \mathrm{~S}$ & 1.732 \\
\hline 14 & DEqn3S17a $\mathrm{a}^{\mathrm{a}}$ & 347.0959 & $\mathrm{C}_{18} \mathrm{H}_{20} \mathrm{O}_{5} \mathrm{~S}$ & 0.903 \\
\hline 15 & 349@0.90 & 349.1115 & $\mathrm{C}_{18} \mathrm{H}_{22} \mathrm{O}_{5} \mathrm{~S}$ & 0.901 \\
\hline 16 & 353@1.04 & 353.1428 & $\mathrm{C}_{18} \mathrm{H}_{26} \mathrm{O}_{5} \mathrm{~S}$ & 1.035 \\
\hline 17 & 465@1.71 & 465.2494 & $\mathrm{C}_{25} \mathrm{H}_{38} \mathrm{O}_{8}$ & 1.710 \\
\hline 18 & 511@1.18 & 511.2913 & $\mathrm{C}_{27} \mathrm{H}_{44} \mathrm{O}_{9}$ & 1.182 \\
\hline 19 & 369@1.14 & 369.1741 & $\mathrm{C}_{19} \mathrm{H}_{30} \mathrm{O}_{5} \mathrm{~S}$ & 1.135 \\
\hline 20 & DEq3S17b ${ }^{a}$ & 349.1115 & $\mathrm{C}_{18} \mathrm{H}_{22} \mathrm{O}_{5} \mathrm{~S}$ & 0.928 \\
\hline 21 & 385@0.56 & 385.1690 & $\mathrm{C}_{19} \mathrm{H}_{30} \mathrm{O}_{6} \mathrm{~S}$ & 0.562 \\
\hline 22 & 371@1.48 & 371.1898 & $\mathrm{C}_{19} \mathrm{H}_{32} \mathrm{O}_{5} \mathrm{~S}$ & 1.476 \\
\hline 23 & 379@1.02 & 379.1221 & $\mathrm{C}_{19} \mathrm{H}_{24} \mathrm{O}_{6} \mathrm{~S}$ & 1.021 \\
\hline 24 & 413@0.86 & 413.2003 & $\mathrm{C}_{21} \mathrm{H}_{34} \mathrm{O}_{6} \mathrm{~S}$ & 0.855 \\
\hline 25 & 355@1.13 & 355.1585 & $\mathrm{C}_{18} \mathrm{H}_{28} \mathrm{O}_{5} \mathrm{~S}$ & 1.132 \\
\hline 26 & 413@1.90 & 413.2003 & $\mathrm{C}_{21} \mathrm{H}_{34} \mathrm{O}_{6} \mathrm{~S}$ & 1.896 \\
\hline 27 & 397@2.28 & 397.2054 & $\mathrm{C}_{21} \mathrm{H}_{34} \mathrm{O}_{5} \mathrm{~S}$ & 2.276 \\
\hline 28 & 413@1.05 & 413.2003 & $\mathrm{C}_{21} \mathrm{H}_{34} \mathrm{O}_{6} \mathrm{~S}$ & 1.045 \\
\hline 29 & 351@0.83 & 351.1272 & $\mathrm{C}_{18} \mathrm{H}_{24} \mathrm{O}_{5} \mathrm{~S}$ & 0.833 \\
\hline 30 & 365@0.91 & 365.1064 & $\mathrm{C}_{18} \mathrm{H}_{22} \mathrm{O}_{6} \mathrm{~S}$ & 0.906 \\
\hline 31 & 415@0.79 & 415.2162 & $\mathrm{C}_{21} \mathrm{H}_{36} \mathrm{O}_{6} \mathrm{~S}$ & 0.789 \\
\hline 32 & 415@1.10 & 415.2162 & $\mathrm{C}_{21} \mathrm{H}_{36} \mathrm{O}_{6} \mathrm{~S}$ & 1.102 \\
\hline 33 & 353@1.29 & 353.1428 & $\mathrm{C}_{18} \mathrm{H}_{26} \mathrm{O}_{5} \mathrm{~S}$ & 1.285 \\
\hline 34 & 415@0.72 & 415.2162 & $\mathrm{C}_{21} \mathrm{H}_{36} \mathrm{O}_{6} \mathrm{~S}$ & 0.723 \\
\hline 35 & $\mathrm{E} 2-3 \mathrm{~S} 17 \mathrm{~b}^{\mathrm{a}}$ & 351.1272 & $\mathrm{C}_{18} \mathrm{H}_{24} \mathrm{O}_{5} \mathrm{~S}$ & 1.015 \\
\hline 36 & 395@2.20 & 395.1898 & $\mathrm{C}_{21} \mathrm{H}_{32} \mathrm{O}_{5} \mathrm{~S}$ & 2.199 \\
\hline 37 & 399@2.29 & 399.2211 & $\mathrm{C}_{21} \mathrm{H}_{36} \mathrm{O}_{5} \mathrm{~S}$ & 2.287 \\
\hline 38 & 385@0.59 & 385.1690 & $\mathrm{C}_{19} \mathrm{H}_{30} \mathrm{O}_{6} \mathrm{~S}$ & 0.593 \\
\hline 39 & 351@0.89 & 351.1272 & $\mathrm{C}_{18} \mathrm{H}_{24} \mathrm{O}_{5} \mathrm{~S}$ & 0.891 \\
\hline 40 & 353@1.24 & 353.1428 & $\mathrm{C}_{18} \mathrm{H}_{26} \mathrm{O}_{5} \mathrm{~S}$ & 1.242 \\
\hline 41 & 385@0.55 & 385.1690 & $\mathrm{C}_{19} \mathrm{H}_{30} \mathrm{O}_{6} \mathrm{~S}$ & 0.546 \\
\hline 42 & 367@1.45 & 367.1585 & $\mathrm{C}_{19} \mathrm{H}_{28} \mathrm{O}_{5} \mathrm{~S}$ & 1.450 \\
\hline 43 & $\mathrm{DEqn}_{3} \mathrm{~S} 17 \mathrm{~b}^{\mathrm{a}}$ & 347.0959 & $\mathrm{C}_{18} \mathrm{H}_{20} \mathrm{O}_{5} \mathrm{~S}$ & 0.790 \\
\hline 44 & 387@0.73 & 387.1847 & $\mathrm{C}_{19} \mathrm{H}_{32} \mathrm{O}_{6} \mathrm{~S}$ & 0.725 \\
\hline 45 & 387@0.68 & 387.1847 & $\mathrm{C}_{19} \mathrm{H}_{32} \mathrm{O}_{6} \mathrm{~S}$ & 0.682 \\
\hline 46 & 395@2.11 & 395.1898 & $\mathrm{C}_{21} \mathrm{H}_{32} \mathrm{O}_{5} \mathrm{~S}$ & 2.113 \\
\hline 47 & 413@1.11 & 413.2003 & $\mathrm{C}_{21} \mathrm{H}_{34} \mathrm{O}_{6} \mathrm{~S}$ & 1.111 \\
\hline 48 & 413@2.07 & 413.2003 & $\mathrm{C}_{21} \mathrm{H}_{34} \mathrm{O}_{6} \mathrm{~S}$ & 2.067 \\
\hline 49 & 413@1.14 & 413.2003 & $\mathrm{C}_{21} \mathrm{H}_{34} \mathrm{O}_{6} \mathrm{~S}$ & 1.138 \\
\hline 50 & 413@1.01 & 413.2003 & $\mathrm{C}_{21} \mathrm{H}_{34} \mathrm{O}_{6} \mathrm{~S}$ & 1.010 \\
\hline 51 & 351@1.10 & 351.1272 & $\mathrm{C}_{18} \mathrm{H}_{24} \mathrm{O}_{5} \mathrm{~S}$ & 1.105 \\
\hline 52 & 511@1.86 & 511.2913 & $\mathrm{C}_{27} \mathrm{H}_{44} \mathrm{O}_{9}$ & 1.863 \\
\hline 53 & 377@0.93 & 377.1064 & $\mathrm{C}_{19} \mathrm{H}_{22} \mathrm{O}_{6} \mathrm{~S}$ & 0.931 \\
\hline 54 & 385@1.11 & 385.1690 & $\mathrm{C}_{19} \mathrm{H}_{30} \mathrm{O}_{6} \mathrm{~S}$ & 1.107 \\
\hline 55 & 367@1.19 & 367.1585 & $\mathrm{C}_{19} \mathrm{H}_{28} \mathrm{O}_{5} \mathrm{~S}$ & 1.193 \\
\hline 56 & 413@2.03 & 413.2003 & $\mathrm{C}_{21} \mathrm{H}_{34} \mathrm{O}_{6} \mathrm{~S}$ & 2.029 \\
\hline 57 & 385@0.62 & 385.1690 & $\mathrm{C}_{19} \mathrm{H}_{30} \mathrm{O}_{6} \mathrm{~S}$ & 0.622 \\
\hline 58 & 381@1.19 & 381.1377 & $\mathrm{C}_{19} \mathrm{H}_{26} \mathrm{O}_{6} \mathrm{~S}$ & 1.193 \\
\hline 59 & 413@1.23 & 413.2003 & $\mathrm{C}_{21} \mathrm{H}_{34} \mathrm{O}_{6} \mathrm{~S}$ & 1.228 \\
\hline 60 & 413@1.06 & 413.2003 & $\mathrm{C}_{21} \mathrm{H}_{34} \mathrm{O}_{6} \mathrm{~S}$ & 1.064 \\
\hline
\end{tabular}




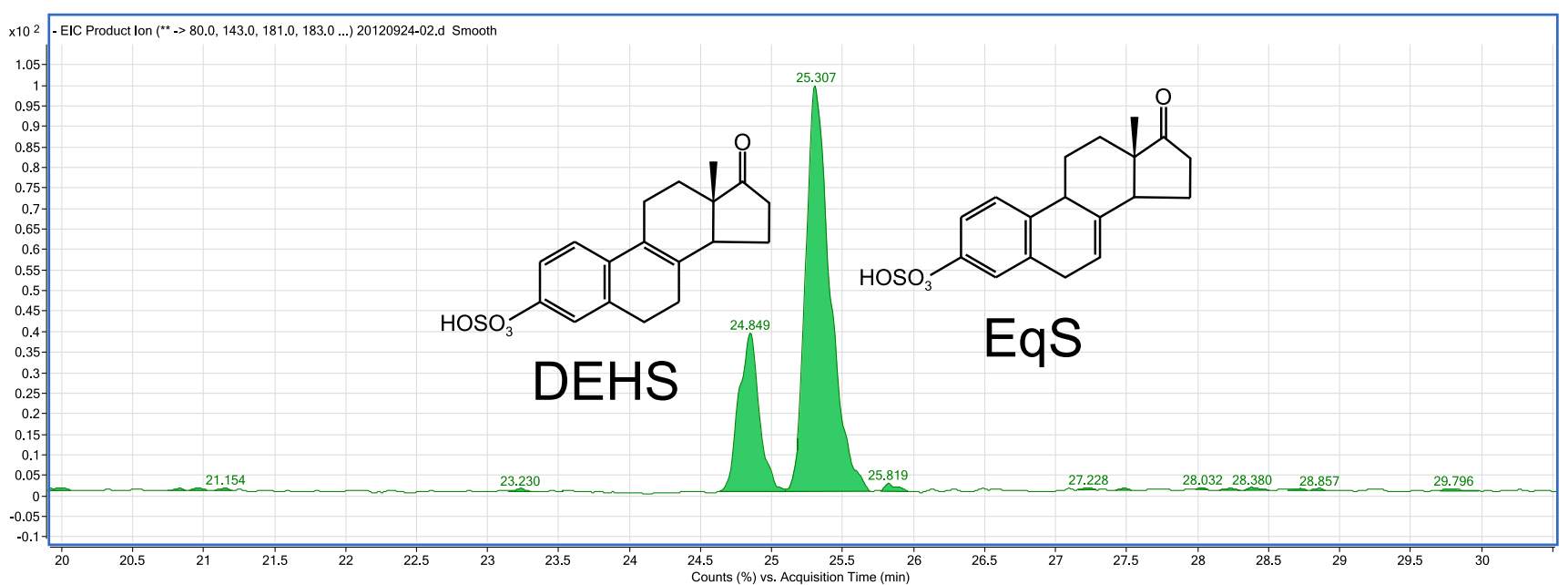

Fig. 1. The extracted ion chromatogram is shown of the separation of DHES and EqS peaks with a resolution of 1.8

\section{Method Reproducibility}

The method developed was tested in different laboratories to examine data reproducibility. Three selected samples of conjugated estrogens tablets in different strengths were used in the test at another two FDA laboratories. The same LC-MS setup (UHPLC column and instruments settings) and a testing protocol outlined in a Draft Guidance was followed (14). The steroidal components identified were compared to the list in Table II based on the relative retention time and the mass $(\mathrm{m} / \mathrm{z})$ value. The normalized relative peak areas of the top 60 components from the three laboratories were compared using one-way ANOVA to detect any significant differences in the results.

\section{RESULTS AND DISCUSSION}

Previous experience in developing a LC-MS method for conjugated estrogens (11) led to the method development strategy used here. In the past decade, column chemistries,

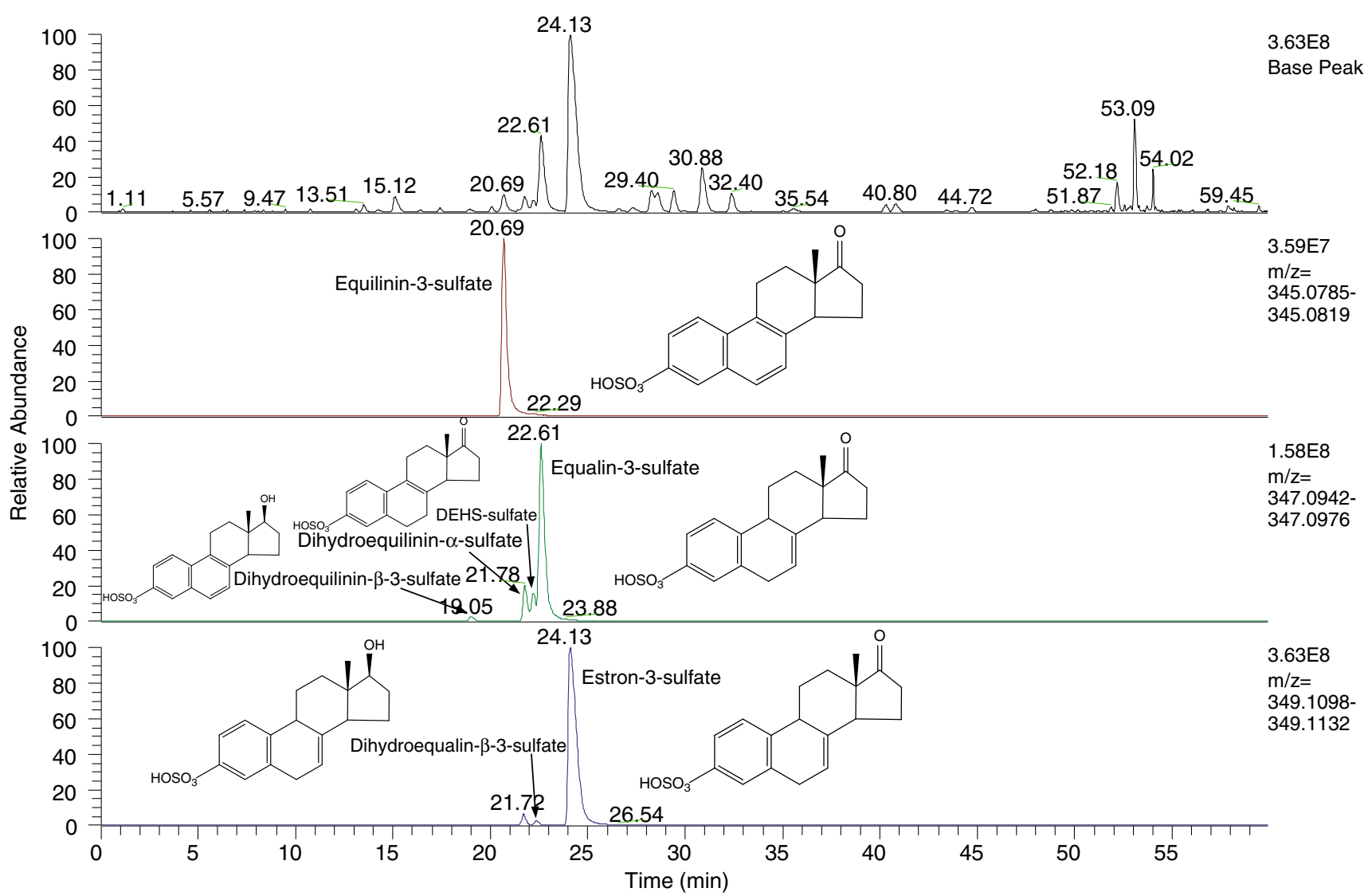

Fig. 2. Total ion chromatogram (top) of the conjugated estrogen compounds isolated from Premarin. Extracted ion chromatograms of ions $m / z$ 345.0802, 347.0959, and 349.1115 (second, third, or bottom panel, respectively) showing multiple species at multiple $\mathrm{m} / \mathrm{z}$ 
1442

Levy et al.

Table III. The Structures of the Known Compounds Are Shown with Their Calculated $\mathrm{m} / \mathrm{z}$

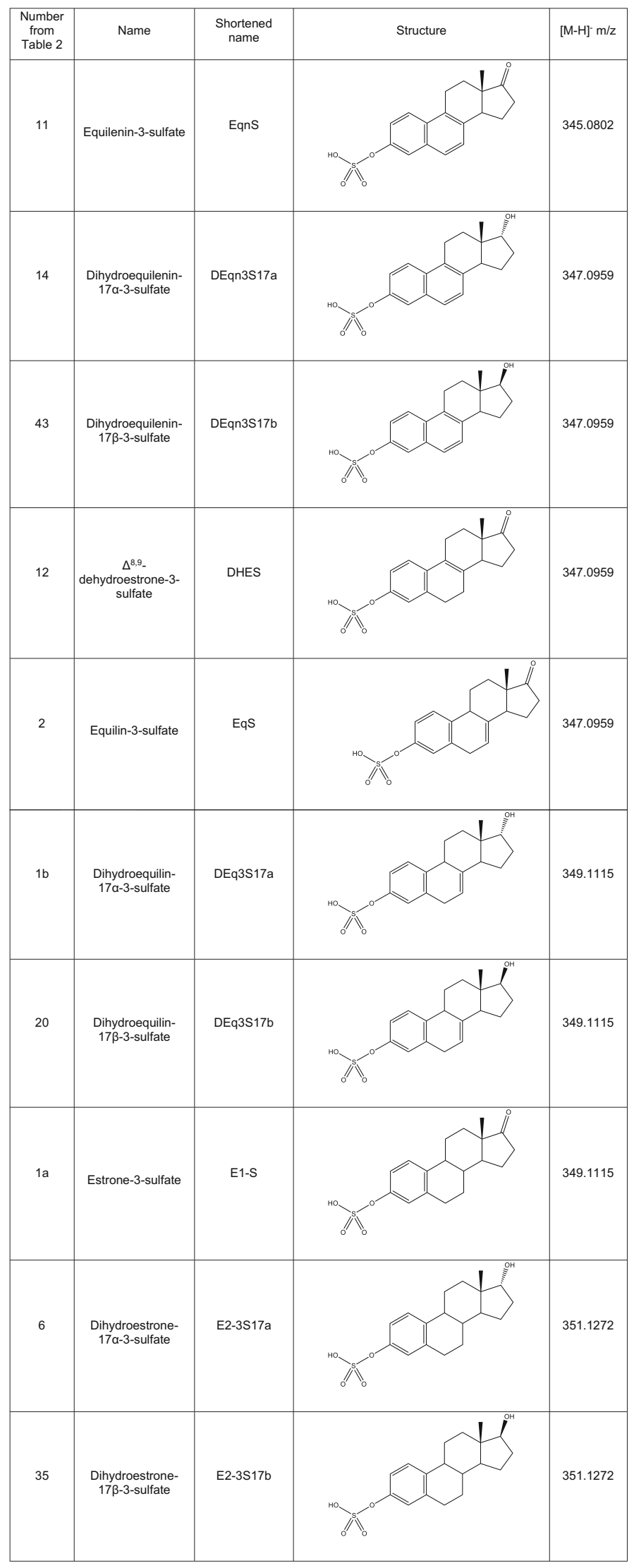


column stability, and column resolution have improved to the point where this method was revisited with more modern technologies (15). Neither hypercarb nor zirconium columns were reassessed due to the lack of their availability in a UHPLC format. A water/acetonitrile gradient did not provide adequate separation of the DHES and EqS peaks on any of the columns chosen. A Waters Acquity BEH C18 2.1×150 mm column provided the best resolution (resolution=1.8) of DHES and EqS with a methanol-based gradient (Fig. 1) and was used for all further experiments. See Supplemental Figure 1 for information on chromatography with other types of columns tested.

In order to ensure reproducibility and robustness of the system, retention times and peak areas were monitored across technical replicates using selected multiple reaction monitoring $(\mathrm{MRM})$ transitions for equilin-3-sulfate $(\mathrm{EqS}), \Delta^{8,9}$ dehydroestrone-3-sulfate (DHES), dihydroequilin-17 $\beta$-3sulfate (DEq3S17b), estrone-3-sulfate (E1-S), dihydroequilin-17 $\alpha-3$-sulfate (DEq3S17a), and dihydroestrone-17 $\beta$-3-sulfate (E2-3S17b). The MRM studies were performed using a triple quadrupole mass spectrometer, as described previously. The average retention time \% RSD was $0.23 \%$ (range 0.22 to $0.24 \%$ ) and the peak area precision ranged from 2.3 to $7.5 \%$ (Supplemental Table 2). Over 1 month, multiple sample isolates were tested for relative retention time reproducibility monitoring equilenin-3-sulfate (EqnS), dihydroequilenin-17 $\beta$-3-sulfate (DEqn3S17b) dihydroequilenin-17 $\alpha$-3-sulfate (DEqn3S17a), DHES, DEq3S17b, EqS, E1-S, E2-3S17b, and dihydroestrone-17 $\alpha-3-$ sulfate (E2-3S17a). The average \%RSD across the peaks was
$0.34 \%$ ranging from 0.12 to $0.71 \%$. Together, these data indicate the column chromatography was reproducible, robust, and suitable for the marketplace analysis of conjugated estrogens samples.

Conjugated estrogens samples were prepared as described and were analyzed by the LC-MS protocol. A total ion chromatogram for the conjugated estrogen elution is shown in Fig. 2 (top panel). All ten sulfated estrogens that are reported in the USP monograph are identified and reported in Table II. The identity of these ions was verified in the method development stage using product ion spectra comparisons to standards. Many ions were detected at low levels during the LC-MS of conjugated estrogens $(>1000)$. In order to determine which steroidal components were consistently present, the top 250 compounds were compared in all lots. The compounds present in all spectra at a peak area of $0.1 \%$ or greater, when compared to the total peak area, were retained (Table II). These components were filtered by accurate mass and mass defect to ensure the putative atomic composition was indicative of a steroidal conjugate (sulfate or glucuronide). For example, the extracted ion chromatogram for the species with $m / z, 345.0802$ (Fig. 2, second panel) shows one peak at retention time 20.69 min corresponding to the EqnS peak. Extracted ion chromatograms for isomers with $\mathrm{m} / \mathrm{z}$ corresponding to 347.0959 (Fig. 2, third panel) or $\mathrm{m} / \mathrm{z}$ 349.1115 are also shown (Fig. 2, bottom panel).

Those conjugated estrogen components with known structures (USP monograph) are shown in Table III and were identified by comparing their product ion spectra to the spectra of synthetic standards. The product ion spectra were
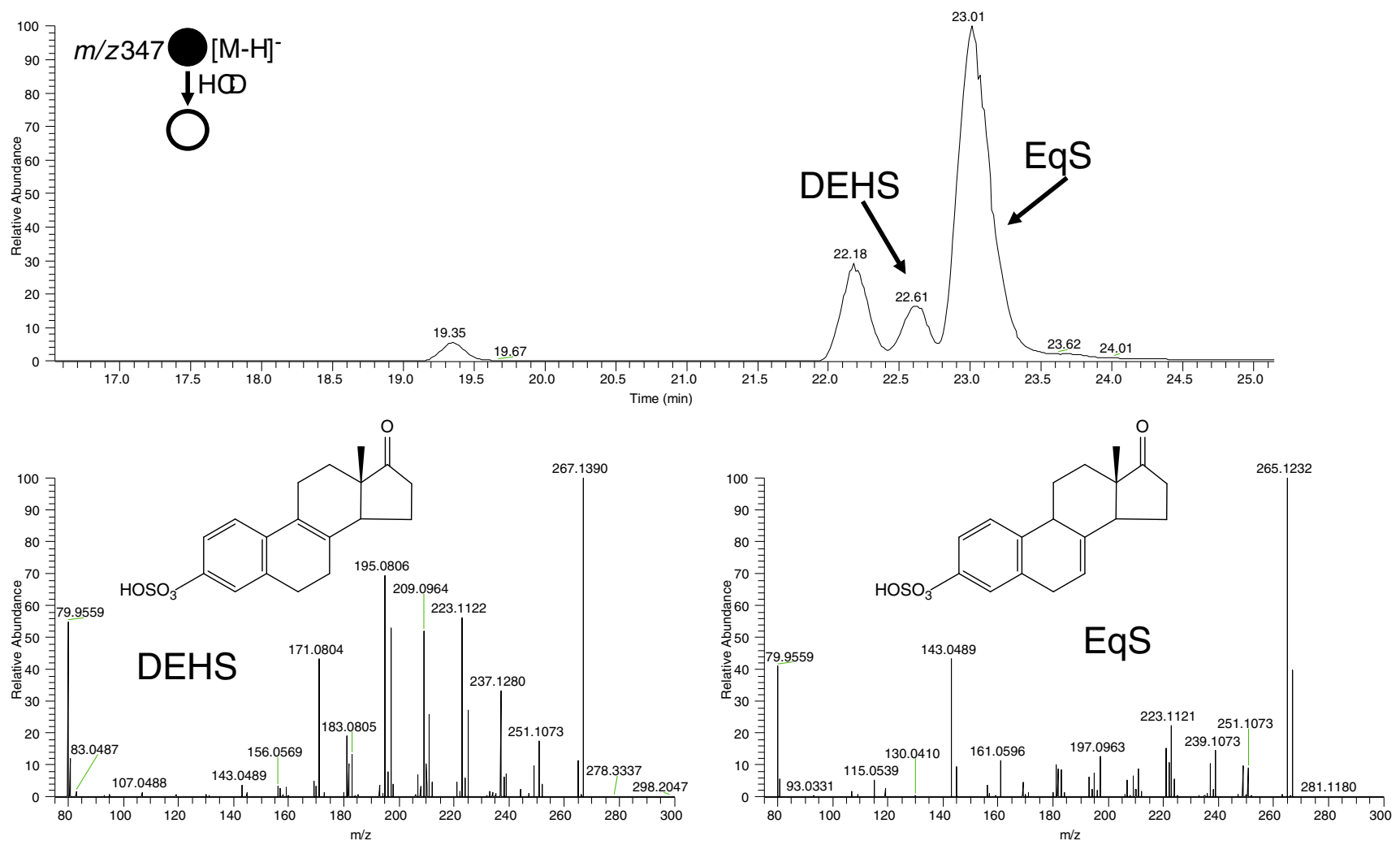

Fig. 3. Product ion spectra of $\Delta^{8,9}$-dehydroestrone-3-sulfate and equilin-3-sulfate after HCD at $75 \%$ NCE 
generated by higher energy collision dissociation (HCD) at $75 \%$ normalized collision energy (NCE). Figure 3 shows two isomeric sulfated equilins that differ by the position of one double bond, DHES and EqS. The prominent $\mathrm{m} / z 143$ fragment in EqS is caused by a break through the $\mathrm{C}$ ring of the core steroid structure. This fragmentation is not possible for DHES because of the position of the double bond. During development, the product ion spectra of the ten sulfated estrogens in the USP monograph (Table III) allowed us to identify each known compound during chromatographic optimization where retention order of compounds may be different for each column. Other sulfated estrogenic compounds representing metabolites of the ones in Table III were tentatively identified using their product ion spectra. The estrogens in conjugated estrogens can be identified using product ion spectra, but the progesterone and androgen metabolites product ion spectra shows only two ions $\mathrm{m} / \mathrm{z}$ 79.9574 and $\mathrm{m} / \mathrm{z}$ 96.9601, corresponding to $\mathrm{SO}_{3}{ }^{-}$and $\mathrm{HSO}_{4}{ }^{-}$. These ions indicate a sulfated conjugate, but do not offer additional structural information. Efforts are being made to analyze these components using different methods (e.g., LCMALDI-MS/MS), and the results will be reported in a separate publication.

The top 60 compounds represent over 95\% content (based on total peak area) of steroidal components when the top 250 compounds were analyzed using the 23 lots of conjugated estrogens tablets. These compounds (top 60) were consistently present at a level above $0.1 \%$ of the total peak area and can be used to represent the steroidal components in conjugated estrogens for assessing API sameness (14). In the USP monograph, the content of the top three components (E1-S, EqS, DEq3S17a) are used to determine the relative amount of other components and the label claim using the GC method. In the current study, we evaluated two approaches in which either the top three components or the top 60 components (i.e., the sum of the corresponding mass spectral peak area) is used as the base to normalize the relative peak area of individual component. It is found that the standard deviation (SD) of the sum of 60 components is 0.047 when the sum of top three is used as the base, while the $\mathrm{SD}$ of the sum of the top three components is 0.012 when the sum of top 60 is used as the base. Therefore, based on the results, the relative peak area is normalized using the total peak area of the top 60 components.

As described previously, a total of 23 lots of Premarin tablets were analyzed using the LC-MS method to assess the lot-to-lot variability of each component. We sorted the 60 components according to its relative peak area in descending order. The first 15 components were found on average have relative peak area $1 \%$ or greater per component (Fig. 4, top panel) while the components 16-60 typically represent less than $1 \%$ (relative peak area) per component (Fig. 4, bottom panel). When the associated 10 and 90 data percentiles were used to represent the variability of each component as shown in Fig. 4, the variability of the first 15 components is relatively small, but in contrast, it varies a lot for the rest 45 components. In some cases, it might be twofold or threefold different from the average value. Beyond the top 60 components, it is difficult to identify consistently present components, as they tend to be low abundant peaks and cannot be consistently detected. Such data indicate while the primary components of conjugated estrogens are consistently present at higher amount with small variation, lower abundance species are variable, and may not be present in every lot.

The purpose of the current study is to develop a LC-MS method that can identify steroidal components consistently present in conjugated estrogens and measure their relative peak areas. It is not intended to be a quantitative method to determine the absolute amount of each steroidal component. Therefore, it is important to assess the data reproducibility when the method is deployed in different laboratories. Based on the testing results of three samples of Premarin tablets at different strengths in three laboratories, the 60 steroidal components can correctly detected and identified based on their relative retention times and $\mathrm{m} / \mathrm{z}$. In addition, one-way ANOVA was applied to detect any significant differences among the results when the values of relative peak area
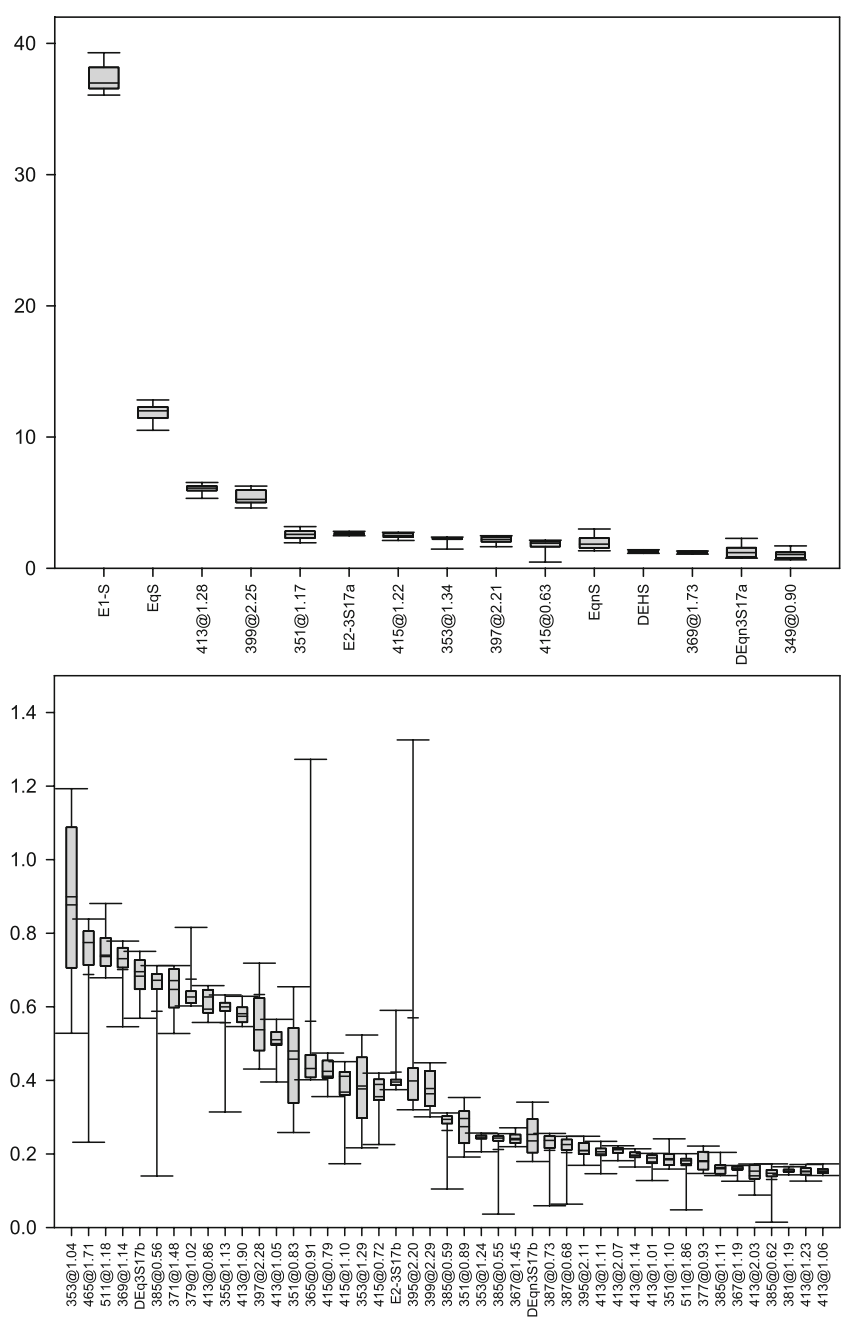

Fig. 4. The variation in peak area was plotted for each of the top 60 components using SigmaPlot 12.3. The median value is displayed as the black bar within the box with the 25th and 75th percentiles as the lower and upper boundaries of the box, respectively, and the 10th and 90th percentiles shown as the error bars. The top panel shows the data for the 15 most abundant compounds and the peak areas are tightly controlled. The bottom panel shows the data for compounds 16-60 with the relative variation being much higher for these lower abundance peaks 
were compared. The $p$ value $(p \approx 1)$ indicates no significant difference was observed. Thus, the data of three testing samples were reproduced, and the LC-MS method is reliable.

\section{CONCLUSIONS}

The use of conjugated estrogens purified from pregnant mares' urine as hormone replacement therapy in the treatment of indications due to menopause has long been established, but the approval of generic conjugated estrogens products has been halted due to lack of analytical methods that can provide comprehensive characterization of the active ingredient of Premarin tablets. Using the LC-MS method outlined here, a total of 60 steroidal components were defined, based on their $\mathrm{m} / \mathrm{z}$ and retention time, which were consistently present in the 23 lots of Premarin tablets analyzed. These lots were manufactured over 2 years, and the lot-to-lot variation of drug product was captured in the results. The ten conjugated estrogens identified in the USP monograph and other additional estrogens reported elsewhere are among the 60 steroidal components reported here. The LC-MS method was tested in different laboratories using multiple samples, and the obtained results were reproducible among laboratories. The large number of steroidal components defined in this work and the measurements of their relative contents may provide a scientific method to assess the sameness of active ingredients for conjugated estrogens products.

\section{REFERENCES}

1. McEwen BS. Invited review: estrogens effects on the brain: multiple sites and molecular mechanisms. J Appl Physiol (1985). 2001;91(6):2785-801.

2. Bhavnani BR, Stanczyk FZ. Pharmacology of conjugated equine estrogens: efficacy, safety and mechanism of action. J Steroid Biochem Mol Biol. 2014;142:16-29.
3. Ansbacher R. The pharmacokinetics and efficacy of different estrogens are not equivalent. Am J Obstet Gynecol. 2001;184(3):255-63.

4. Wren BG, Brown LB, Routledge DA. Differential clinicalresponse to estrogens after menopause. Med J Aust. 1982;2(7):329-32.

5. Barrett-Connor E, Young R, Notelovitz M, Sullivan J, Wiita B, Yang HM, et al. A two-year, double-blind comparison of estrogen-androgen and conjugated estrogens in surgically menopausal women - Effects on bone mineral density, symptoms and lipid profiles. J Reprod Med. 1999;44(12):1012-20.

6. Lindsay R, Hart DM, Aitken JM, MacDonald EB, Anderson JB, Clarke AC. Long-term prevention of postmenopausal osteoporosis by oestrogen. Evidence for an increased bone mass after delayed onset of oestrogen treatment. Lancet. 1976;1(7968):1038-41.

7. Woodruff JD, Pickar JH. Incidence of endometrial hyperplasia in postmenopausal women taking conjugated estrogens (Premarin) with medroxyprogesterone acetate or conjugated estrogens alone. The Menopause Study Group. Am J Obstet Gynecol. 1994;170(5 Pt 1):1213-23.

8. USP 38-NF 33 (United States Pharmacopeia Convention) Conjugated Estrogens, USP. 2015;3390-3392.

9. Stanczyk FZ. Estrogens used for replacement therapy in postmenopausal women. Gynecol Endocrinol. 2001;15(S4):1725.

10. Woodcock J. Conjugated estrogens-letter from Dr. Janet Woodcock 1997. Available from: http://www.fda.gov/Drugs/ DrugSafety/InformationbyDrugClass/ucm168836.htm.

11. Reepmeyer JC, Brower JF, Ye H. Separation and detection of the isomeric equine conjugated estrogens, equilin sulfate and delta 8,9 -dehydroestrone sulfate, by liquid chromatography-electrospray-mass spectrometry using carboncoated zirconia and porous graphitic carbon stationary phases. J Chromatogr A. 2005;1083(1-2):42-51.

12. Jayatilaka A, Poole CF. Computer-assisted optimization of the gas chromatographic separation of equine estrogens. J Chromatogr. 1993;617(1):19-27.

13. Shimada K, Mitamura K, Higashi T. Gas chromatography and high-performance liquid chromatography of natural steroids. J Chromatogr A. 2001;935(1-2):141-72.

14. Draft Guidance on Conjugated Estrogens. 2014. Available from: h t t p : / / w w w.f d a.g o v/d ow n lo a d s/D r u g s / GuidanceComplianceRegulatoryInformation/Guidances/ UCM428204.pdf.

15. Gosetti F, Mazzucco E, Gennaro MC, Marengo E. Ultra high performance liquid chromatography tandem mass spectrometry determination and profiling of prohibited steroids in human biological matrices. A review. J Chromatogr B Anal Technol Biomed Life Sci. 2013;927:22-36. 